\title{
Review on Post-Harvest Processing Operations Affecting Coffee (Coffea Arabica L.) Quality in Ethiopia
}

\author{
Mikru Tesfa (MSC.) \\ Jimma Agricultural Research Center (JARC)
}

\begin{abstract}
Coffee is the most important crop in the national economy of Ethiopia and continues to be still the leading export commodity. Despite the economic importance, productivity and quality of the crop is very low. Improper post harvest processing techniques such as harvesting immature cherries, lack of sorting during grading and processing, improper drying without considering drying time, drying place, thickness layer and drying material, transportation, storage, over fermentation etc largely contribute to the decline in coffee quality of Ethiopia. It is widely agreed that traditional hand-picking and husbandry labor, as opposed to mechanical harvest, produce the best quality green coffee by decreasing the percentage of defects in coffee batches. Then, depending on the postharvest process, strong consequences on coffee quality can be observed. However, lack of information on the effects of post harvest processing and drying on quality necessitates a comprehensive study. Therefore, work was carried out to review such constraints that affect coffee quality and to give more emphasis especially in small scale coffee production of Ethiopia for exporting premium quality coffee in higher percentage.
\end{abstract}

Keywords: Coffee post harvest, Coffee quality

DOI: $10.7176 / \mathrm{JEES} / 9-12-04$

Publication date: December $31^{\text {st }} 2019$

\section{INTRODUCTION}

Ethiopia is the original home of Coffea arabica L, and thus, possesses the largest diversity in coffee genetic resources (Mayne et al., 2002; Girma, 2003). Coffee is one of the most popular beverages in the world (Nebesny and Budryn, 2006), and the most traded commodity second after oil (Ponte, 2002). Arabica coffee is more economical and it represent three quarters of the world coffee productions (Kristina, 2011). Coffee had been and still contributes the Lion's share in the national economy being the leading source of foreign exchange earnings (Taye et al., 2011). It is an essential commodity to the livelihood of millions of Ethiopians. The major coffee producing regions in the country are Oromiya and Southern Nations Nationalities and Peoples Region.

The total area coverage of coffee in Ethiopia is estimated to be around 800,000 ha of which about $95 \%$ is produced by 1.2 million small scale farmers. Currently, Ethiopia exports 170,000 tons and has a domestic consumption estimated to be about 50\% of the total production (Esayas, 2009; Aklilu and Ludi, 2010). Coffee processing in Ethiopia is executed by both dry and wet processing methods, of which sun drying is widely practices by farmers and hence it accounts for $71 \%$ of the total while washed coffee preparation accounts $29 \%$ (Subedi, 2010). Regardless of the importance of the crop, poor postharvest processing techniques largely contribute to the decline in coffee quality (Bayetta et al., 1998; Behailu et al., 2008). In general, the traditional processing practices employed by producers have imparted a negative impact on Ethiopian coffee quality (Behailu et al., 2008; Lower et al., 2007).

Accordingly, few research attempts have been made to optimize with regard to fermentation, drying depth and time of storage for wet processing of coffee (Behailu et al., 2008). However, post-harvest processing of unwashed coffee at field level has received only a limited attention of researchers. This calls for a concerted effort to identify post-harvest practices for sun drying of coffee to come up with technical recommendations to ensure premium coffee quality. Coffee quality has critical importance to the coffee industry. It is defined differently in each stage of its production (Leroy et al., 2006). Quality is a product that has desirable clean raw and roasted appearance, attractive flavor and good cup taste (balanced acidity and body) (Behailu et al., 2008). Factors that determine coffee quality are numerous. The genotype, climatic conditions, soil characteristics, agricultural practices, harvesting methods and post harvest processing techniques are the major attributes for deterioration of coffee quality.

Ethiopia produces large volume of coffee beans every year with 397, 500,000 kg in 2014 alone, ranking first in Africa and fifth in world (ICO, 2015). Coffee growing and drinking spread around the world starting in the Horn of Africa, specifically Southwestern highlands of Ethiopia are the birth place and home to Arabica coffee. The majority of coffee produced in Ethiopia is forest-based traditional coffee production systems which mainly include: forest coffee, semi-forest coffee, garden coffee and plantation coffee. Accordingly, over one million small-scale coffee farming households produce about $90 \%$ of Ethiopia's coffee. Moreover, about $25 \%$ of the Ethiopian population depends, directly or indirectly on coffee production, processing and marketing (Esayas, 2005). It is estimated that $40 \%$ of coffee quality is determined in the field, $40 \%$ at post-harvest primary processing and $20 \%$ at secondary/export processing and handling including storage (Richard, 2007). Ethiopia is 
known to have broad diversities of coffee varieties each with its own unique liquor attributes: aroma, taste, and flavor, that vary significantly among the different coffee growing regions owing to different botanical, ecological, and environmental conditions in different areas. There is a growing commercial interest in the international market to trace and access single origin coffee, pure and unmixed with other origins in the specialty coffee concept. Quality is a determining factor in the price of coffee beans. In fact, in Ethiopia the quality determines whether it can be exported or must be sold locally. Moreover, quality defines whether the coffee will be bought at a standard commodity price or may acquire a "specialty" price, which is much higher. Generally, coffee quality comes from a combination of the botanical variety, topographical conditions, weather conditions, and the care taken during growing, harvesting, processing, storage, export preparation and transport (ITC, 2002).

Interestingly, the quality of Arabica coffee in Ethiopia has its own reputation, not only because of the richness in coffee genetic diversity, but also in agro-ecology and vegetation covers. Ethiopia's wet-processed coffee is well known for its high quality in the world market.

Cup quality is a complex characteristic which depends on a series of factors such as the species or variety (genetic factors), environmental conditions (ecological factors), agronomical practices (cultivation factors), processing systems (post-harvest factors), storage conditions, industrial processing, preparation of the beverage and taste of the consumer (Moreno et al., 1995). In Ethiopia the quality of coffee produced by farmers has been deteriorating from time to time. Moreover, factors that determine coffee quality are genotypes, climatic conditions, and soil characteristics of the area, agronomic practices, harvesting methods and timing, post harvest processing techniques, grading, packing, storage conditions and transporting, all contribute either exaltation or deterioration of coffee quality (Behailu et al., 2008). Similarly, Damanu (2008), reported coffee quality as a combination of the botanical variety, topographical conditions, and climatic conditions and the care taken during growing, harvesting, storage, exports preparation and transport. The aim of this graduate seminar is to review post harvest processing operations that affect coffee quality.

\section{Botanical Description of Coffee Arabica}

Coffee belongs to the family Rubiaceae and the genus Coffea (Wrigley, 1988). In the genus Coffea, there are about 100 species all of which originated in Africa (Wrigley, 1988; Coste, 1992; Pearl et al., 2004), and are woody, ranging from small shrubs to large robust trees with a height of up to $10 \mathrm{~m}$, either deciduous or evergreen. Leaf colour may be yellow, dark green, bronze and purple-green with the size of 1 to $40 \mathrm{~cm}$ in length. Species differ considerably in fruit taste, ranging from good and sweet-flavoured to distinctly inedible ones. Fruit size ranges from pea-sized to a good-sized plum. Flowers can be small, unattractive, and scentless or large and densely clustered with abundant fragrance.

Arabica coffee is the only known tetraploid $(2 n=4 x=44)$ and self-fertile (over 95\%) species in the genus (Coste, 1992). It is the most widely cultivated coffee since time immemorial (Coste, 1992; Lashermes et al., 1996b). Because Ethiopia is the source of $C$. arabica, considerable natural diversity has been observed in cultivated and wild coffees in the country (Coste, 1992). These characteristics include disease resistance, high yield, and best quality. This great diversity is a genetic reservoir for coffee breeders (Prakash et al., 2002). This is nature's gift to Ethiopia in particular and to the world in general. Currently, there are 37 improved coffee varieties in the country (34 pure lines and 3 hybrids) released since 1977 based on these attributes (Taye, 2010; Belachew et al., 2000; Anzueto et al., 2001). Variations were also observed in green bean biochemical compounds (caffeine, chlorogenic acids, sucrose, and trigonelline) composition (Key et al., 2001, Yigzaw, 2006), tree size and shape, bean size, colour and cup quality (Wondimu, 1998). Montagnon and Bouharmont (1996) classified wild and cultivated coffee accessions from Ethiopia according to their geographic origin using 18 agro-morphological characters. Consumers have come to identify the names of coffee lands, coffee regions, coffee farms, and even coffee plants (Ferguson, 2006).

\section{Coffee Production Status in Ethiopia}

The total area coverage of coffee in Ethiopia is estimated to be around 800,000ha of which about $95 \%$ is produced by 1.2 million small scale farmers. Currently, Ethiopia exports 170,000 tons and has a domestic consumption is estimated to be about $50 \%$ of the total production (Esayas, 2009; Aklilu and Ludi, 2010). Smallholder farmers on less than two hectares of land produce $95 \%$ of Ethiopia's coffee while the remaining five percent is grown on modern commercial farms. Coffee production is important to the Ethiopian economy with more than 15 million people directly or indirectly deriving their livelihoods from coffee. Ethiopia is the largest producer and exporter of coffee in Africa and is the fifth largest coffee producer in the world next to Brazil $(33.72 \%)$, Vietnam (18.86\%), Indonesia (8\%) and Colombia $(7.48 \%)$ by contributing about $4.53 \%$ of total world coffee production in 2013 (Alemseged and Yeabsira, 2014). Ethiopia's land covered with coffee is estimated to be 530,000 hectares in 2012/13 that increased by $25 \%$ from 2008/09 (CSA, 2013). The total coffee production in Ethiopia is about 374,000 tons in $2012 / 13$ which is $8 \%$ lower than the total production of $2011 / 12$ cropping year (ICO, 2014) of the total production more than $65 \%$ was harvested from Oromia region (CSA, 2013). 


\section{Coffee Quality}

According to the International Organization for Standardization (ISO) (2000), Quality is described as "the ability of a set of inherent characteristics of a product, system or process to fulfill requirement of customers and other interested parties". These inherent characteristics can also be called "attributes". For coffee, the definition of quality and the attributes considered have probably evolved through the centuries. But now adays, this definition varies along the production-to-consumer chain (Leroy et al., 2006).

At the farmer level, coffee quality is a combination of production level, price and easiness of culture.

At the exporter or importer level, coffee quality is linked to bean size, lack of defects and regularity of provision, tonnage available, physical characteristics and price.

At the roaster level, coffee quality depends on moisture content, stability of the characteristics, origin, price, biochemical compounds and organoleptic quality (Leroy et al., 2006). It should be noted that each consumer market or country may define its own organoleptic qualities; at the consumer level: coffee quality deals with price, taste and flavor, effects on health and alertness, geographical origin, environmental and sociological aspects (organic coffee, fair trade, etc (ISO, 2000). More specifically, ISO (2004a) defined a standard for green coffee quality (ISO 9116 standard) as, it requires several pieces of information, like the geographical and botanic origins of the coffee, the harvest year, the moisture content, the total defects, the proportion of insect-damaged beans and the bean size. These ISO standards define methods of measurements for several of these qualities such as, defects, moisture content, bean size, some chemical compounds and preparation of samples to perform cup tasting.

According to the definition of quality and standards authority of Ethiopia (QSAE) (2000) a quality is conformance with requirements or fitness for use in which the parties involved in the industry (customer, processor, supplier, etc) should agree on the requirements should be clear to all stake holders involved in the process. On the other hand, Coffee Quality control and auction Center was established with a key objective of maintaining coffee quality control, which in turn facilitates the coffee marketing system to be standard based, and for the betterment /proper functioning of the long coffee supply chain of Ethiopia (Endale, 2008). Coffee has only one value to give the consumer pleasure and satisfaction through flavor, aroma and desirable physiological and psychological effects (Yigzaw, 2005). Therefore coffee quality, especially liquor or cup quality, determines both the relative price and usefulness of a given quantity of coffee (Agwanda et al., 2003). Cup quality, often referred to as drinking quality or liquor quality, is an important attribute of coffee (Muschler, 2001; Agwanda et $a l ., 2003$ ) and acts as yardstick for price determination (Agwanda et al., 2003).

\subsection{Organoleptic (cup) quality of coffee}

When assessing organoleptic quality, one has to take into account that consumers have a specific taste according to their nationality, which leads to an unreliable definition of organoleptic quality (Wintgens, 2004; Leroy et al., 2006). In addition, organoleptic characteristics must be stable, especially for the roaster and the consumer. The smell of the ground-roasted coffee before water added sometimes called fragrance. Then, one can smell the aroma, evaluate the body and perceive taste and flavors. Organoleptic quality measurement relies on overall or sensory evaluation (Leroy et al., 2006). Hence, assessment of coffee organoleptic quality is an extremely demanding exercise; indeed the flavor obtained in a coffee cup is the result of multiple aromatic compounds present in the coffee (more than 800 in the roasted coffee) (Clifford and Wilson, 1985).

\subsection{Physical (raw) quality of coffee}

The International Coffee Organization (ICO, 2001) implemented a Coffee Quality Improvement Program (CQIP) with recommendation to exporting countries. It is not recommended to export coffee with the characteristics having foreign material of non coffee origin; foreign materials of non bean origin, such as pieces of parchment or husk; abnormal beans for shape regularity or integrity; abnormal beans for visual appearance, such as black beans; abnormal beans for taste of the cup after proper roasting and brewing. Bean size, which is usually determined by screening, is of particular importance to roasters since bean of the same size would be expected to roast uniformly. In addition, these size and shape differences of coffee beans were influenced by botanical variety and environmental growth circumstances (Sivetz and Dosrosiier, 1979; EAFCA, 2008).

\section{Post Harvest Processing Operations}

Coffee harvesting: The main factor affecting natural coffee quality is harvesting method. It is widely agreed that traditional hand-picking and husbandry labor, as opposed to mechanical harvest, produce the best quality green coffee by decreasing the percentage of defects in coffee batches (Bertrand et al., 2006). Maturity also has a strong influence on coffee quality. Immature cherries harvesting is most series problem in coffee harvesting. Under rip cherries are very difficult to process and low quality product is produced. One of the main causes of immature harvesting is fear of theft (Yigzaw, 2005). Endale et al. (2008) pointed out that low caffeine content was found in bean harvested at immature stage (unripe). Overripe cherries should not be picked often they are 
already fermenting on the tree leading to very bad off-tastes. A handful of over-fermented beans can spoil the quality of an entire container green bean. Ripe cherries that take too long to be processed will also lead to overfermented beans. It is very important to transport cherries to the factory as soon as possible after harvesting. If this is not possible one can slow down the fermentation rate, and thereby the rate of quality loss, by evenly spreading out the cherries around $10 \mathrm{~cm}$ thick. Of course the cherries should not get indirect contact with soil, dogs, chicken, motorbikes, etc. from over-ripe cherries (Endale et al. 2008). Dried cherries, either on the tree or fallen down on the soil should not be picked. Especially fallen cherries as they pose a health risk because of bacterial infection and development of moulds and Ochratoxin A which is known to cause cancer (Michiel Kuit 2004). The main factor affecting natural coffee quality is harvesting method. Hand picking coffee beans is one method for accomplishing high quality of produces by picking red cherries only. Therefore, it widely agrees that selective hand picking, as opposed to traditional strip and mechanical harvesting, produce the best quality green coffee by decreasing the percentage of defects in coffee batches. Maturation also has a strong influence on coffee quality, and it varies with coffee species. C. arabica early picking of red cherries gives the best coffee cup and physical quality (Bertrand et al., 2006).

Coffee bean sorting and grading: Green coffee is graded and classified for export with the ultimate aim of producing the best cup quality and there by securing the highest price. Although, there is no universal coffee grading and classification system however, some common grading criteria are altitude and/or region, botanical variety, processing methods; bean physical appearance (size, shape and color), number of defects (imperfections), roast appearance and cup quality (flavor, cleanliness, body, acidity, etc) and density of the beans. Determination of amount of defective beans has always been associated with quality. The assessment of defective bean count is done by hand picking all the defects from specified amount of coffee (weight or volume) then grouping similar defects counting, weighting them and finishing up with one number representing the total amount of defects. To determine the amount of defective beans is to weigh them after grouping and then get a percentage of (weigh bases) of a particular defect. Defective (triage) coffee beans are beans rejected after separating the graded ones according to the size and color. Generally according to SCAA grades are: Specialty grade one (no more than 5 full defect/300 gm, no primary defect and quakers are not allowed, Premium grade 2 (no more than 8 full defect/300 gm, primary defect are permitted and 3 quakers are allowed), Exchange grade 3 (having 9 to 23 full defects, 5 quakers are maximum allowed), Below standard grade 4 ( having 24 to 86 defects/300gm) and Off grade 5 ( having greater than 86 defects). Thus, based on one or more of these criteria each coffee producing and exporting country has its own national coffee grading system that fulfills the minimum standard for export (ITC, 2011).

\subsection{Coffee Processing Methods}

The succession of operations in dry and wet processing of coffee general flow chart 


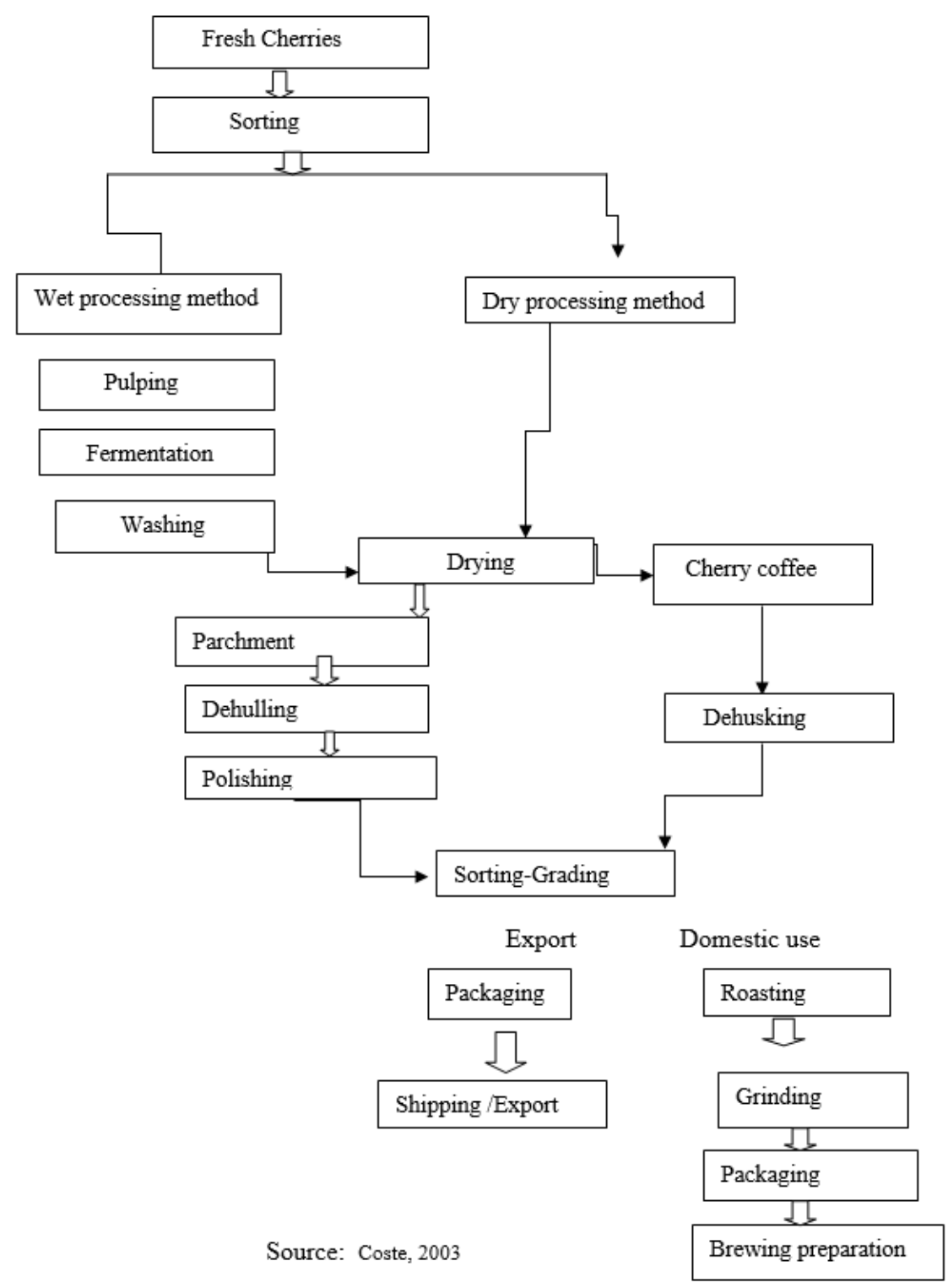

Wet Processing Method: In this processing method, the pulp is separated from the parchment. In this way slippery mucilage is exposed which is commonly removed by a process commonly called fermentation. This is followed by drying and washing of the beans in the parchment. Removal of parchment by hulling gives the clean coffee. The many steps in the wet method of coffee processing make it rather expensive but, if properly carried out, it gives a very high quality coffee (Wanyonyi, 1999).

Coffee Pulping: The beans are separated from the skin and pulp by using a pulping machine that squeezes the berries between fixed and moving surfaces. The flesh and the skin of the fruit are left on one side and the beans, enclosed in their parchment covering, on the other. The clearance between the surfaces is adjusted to avoid damage to the beans. The lighter, immature beans are then separated from the heavier, mature beans through specially designed washing channels or by shaking the beans through a strainer into a tank of water.

Coffee Fermentation: It involves the process that allows the mucilage layer on the parchment to be washed off easily. The beans are stored in fermentation tanks for 2-3 days depending up on the weather condition during which time, the slimy layer of the berry is separate from its parchment like covering, by natural enzymes. Completion of fermentation is determined by washing a bit of the parchment with clean water and then feeling the coffee with the hand. A gritty feel is an indication of the completion of fermentation. Different chemical products like lime, alkaline carbonates can also be used for removal of the mucilage which precipitates the pectines in the form of soluble pectates, which are then easily removed by washing (Mutua, 2000). Natural fermentation of coffee is the function of many parameters, such as environmental, $\mathrm{pH}$, temperature, micro flora and the level of pollution in the water used, variety difference in the ripe cherries used for pulping, its geographical and cultural origin, the standard of picking and minor variations in the processing method (Behailu et al., 2008). Furthermore, Behailu and Solomon (2006) reported that coffee, fermented under shade takes more 
time, shaded fermentation tanks help to achieve uniform fermentation process and better quality coffee than un shaded one. However, the assessment made on wet processed Jimma coffee by Brownbridge and Eyassu (1968) revealed that it is very heterogeneous, containing bones of all shapes, sizes and plain liquor, probably because of such a mixed type characterized by small beans of a lovely green color and exquisite aroma. Under-water soaking of coffee processed by dry fermentation enhanced the appearance of raw and roast quality of Ethiopian coffees consistently compared to coffee processed by dry fermentation only was established by Brownbridge and Sium (1971).

Coffee Soaking and Washing: The main advantage of the soaking was to improve the raw and roast appearance by removing the browning of the coffees which is presumed to originate from degraded sugars and polyphenols as reported by Wootton (1971). After the completion of fermentation which can be found out by gritty feeling, not slippery, the coffee beans are then washed without delay to remove the fermentation break-down products. Delay or insufficient washing at this stage can produce undesirable flavours in final product. Fully wet parchment coffee has a moisture content of 50-54\%. Soaking of parchment under water after complete fermentation for about 12 hours helps in improving the quality of coffee both in colour and taste. The fermented parchment is subjected to wash thoroughly in order to remove the degraded mucilage and acid before soaking (Wickra masinghe et al., 2001). After fermentation and soaking, the parchment coffee is again washed with clean water to remove any dirt or remains of mucilage or sugars. Final washing is done in concrete channels by pushing the parchment with wooden paddles against a stream of water.

Semi- wet Processing method: This is another method of washed coffee processing which is recently introduced to Ethiopia. It is a method of washing coffee immediately after harvesting and pulping without long time fermentation. According to Stump town (2011), semi-washed processing is very similar with wet processed in first step the cherries pulped, but it is dried with mucilage clinging to the outside of the parchment or it is immediately remove mucilage layer entirely from the outside of the parchment by demucilager. Coffee bean that have been processed with the semi-washed method are somewhat similar to wet processed coffee, exhibiting a bright, clean cup with a bit less body than dry processed coffee (Espresso \& coffee guide, 2008). It is a superior quality to that produced by natural methods, which costs less overall, as it is affords a cleaner and more constant flavor to the final coffee. Processing beans in this way is said to reduce the acidity of the final coffee, rendering it more full body and potentially preferable for espresso coffee (Dr Workefied Blog, 2013). Also, recent studies have shown that semi-washed processing in which the mucilage removed by demucilager are a cost efficient and an effective way to consistently produce high quality coffee without the need for fermentation and washing (FAO, 2010).

Dry Processing method: The drying operation is one of the most important steps in the coffee post harvest processing that influences the final quality of the coffee (Corrêal et al., 2006; IBERO, 2005). Drying can affect the physical appearance, the yield at hulling and the taste of the beverage (Aregba et al., 2006). According to Cirovelásquez et al, (2009), drying is one part of the post harvest process that is responsible for the removal of excess moisture to a level that is safe for long time storage without any impact to aroma or taste of the final beverage. Several factors affect the coffee drying process including the drying method, drying air temperature, relative humidity, drying air velocity and the drying time (Corrêa1 et al., 2006). In dry method, whole cherry is dried and when this is finished, the pulp and the parchment are removed in one single operation. This is simple method which includes less labor cost. The cherries are either sun-dried or machine dried with the outer fruit intact until the fruit gets moisture content of $12 \%$. After drying they are de-hulled mechanically, producing beans that are characteristically lower in acidity, sweet, smooth and more complex in flavor than wet processed coffees (Wanyonyi, 1999).

Coffee drying: Drying is considered an important step in quality coffee production, since moisture levels higher than $12 \%$ can promote microbial growth and mycotoxin formation (Reh et al., 2006; Getachew et al., 2015). The main propose of drying is to maintain the moisture content of the parchment optimum for storage. Freshly pulped coffee has a moisture content of about $55 \%$ and that has to be reduced by drying to $11 \%$. This is the ideal level of moisture content required for proper storage, hulling and roasting. In most of the developing countries, sun drying is predominantly used and mainly by the producers' organizations/cooperatives, and the coffee is spread on the wire mesh tables for normally about two weeks in sunny days, until fully dry. Few commercial companies use mechanical drying method (Mutua, 2000). The surface is over dried and shrinks irreversibly to prevent easy movement of moisture from within the bean in an outward direction. Worse than this, the bean may become pale and bleached in appearance signifying flavour deterioration. Field evidences have shown that when drying is done too rapidly under excessively warm temperatures, the valuable cup flavour is largely lost from coffees that otherwise would have been considered excellent (Sivetz and Foote, 2004). Generally, degree of dryness was tested with two methods: dental and digital. The dental method involves peeling the parchment of an individual bean and biting it with incisors. If it is easily dented or even cut by the bite, it is not dry. If a hard bite hardly dents the bean, it is dry. The dental method is subjective and non-accurate method. The digital method relied on a digital coffee moisture meter (tester), when correctly calibrated; it is the best method to 
determine moisture content of coffee.

Dehulling and Dehusking: This is the process of removing husk either from the dry parchment coffee or dry cherry in order to give the commercial green coffee. When the coffee gets to this stage, all intrinsic quality (moisture content, colour) has already been obtained. The different sorting techniques to which it is subjected can only reduce its percentage of defects in coffee beans. Hulling is achieved by creating friction among the beans lying along the screw of machine. It is crucial not to heat the beans during hulling otherwise it will affect the final colour and taste of coffee. There is another final layer closest to bean, called as silverskin, which may or may not be removed during hulling process. For removal of silverskin, separate equipment following hulling called polishers is needed. The green bean received is then subjected for sorting according to density, size and colour (Wanyonyi, 1999).

Coffee Storage: Coffee storage is an important step, since the dried coffee can easily absorb bad flavors or moisture that degrades the quality from the storage area. Once the samples reached their target moisture, farmers or traders should put into a cool dry area away from the potential contaminants, such as cow dung, soils, chickens and smoke sources. The moisture levels were checked frequently to ensure that the levels had equilibrated and stabilized at the target moisture levels. Besides this, due to the inherent imbalance between supply and demand in the coffee market, it is sometimes necessary to store coffee for long period of time in which the length of storage affects the quality of coffee. According to Wintegens (2004), green coffees stored for a longer period described as aged coffee may suffer a loss of their acidity, which is needed for a coffee to have a specialty coffee grade. On the other hand, length and condition of bean storage also affect cup quality (Yigzaw, 2005). Moreover, long time storage under high relative humidity and warm conditions increase bean moisture content and consequently reduce quality in terms of raw and roasted appearance as well as liquor (Woelore, 1995). Even under adequate or optimal storage conditions, coffee beans deteriorate with age. This phenomenon is accelerated when the environment is hot and/or humid and the bean takes off-flavor due to the oxidation of its own fats. If longer storage is sought, it is better to store at a temperature blow $20^{\circ} \mathrm{C}$ and $65 \%$ relative humidity. Anwar (2010) reported that, storage is one of the most important and crucial stage in processing of any agricultural commodity. In case of coffee storage, the goal is to achieve and maintain its commercial value as long as possible by preserving the integrity of the bean with all its characteristics. The need for adequate storage is crucial since coffee beans are living entities in which their viability depends largely on storage condition and food safety has now become an extremely important issue since the effects of toxic substances, which would develop during storage, can cause significant harm to human health. The generally accepted time for green coffee storage under normal conditions is one year.

Coffee Roasting and Grinding: This is the most critical stage during postharvest handling of coffee. The main purpose behind Roasting is to release the aroma, an operation which many coffee lovers insist on performing themselves. A good roaster must be a part artist, and part scientist, to maintain quality and consistency. In the development of flavours, roasting is probably the most important of the steps considered so far. Well roasted coffee should be brown, of varying degrees of darkness, but never black. Both traditional and modern roasters are used, but in order to get better uniform quality of roasted beans, modern (electric) roasters are preferred. The roasting process causes the coffee beans to swell and increase their size by over $50 \%$, while at the same time greatly reducing their weight (Hicks, 2002). Temperature and time are two critical things that have to keep in mind during roasting to obtain better quality coffee. During roasting, the coffee beans are heated at 200-2400 0C about 10-15 minutes depending on the degree of roasting required, which is mainly evaluated by colour. The amount of oil drawn to the surface of the bean due to caramelization of sugar and carbohydrates inside the bean increases proportionately to the length of roasting time. After roasting, coffee does not keep its aroma for long; it is, therefore, better not to roast or not to buy coffee exceeding current needs. It is advisable to keep it in airtight package-aging to prevent light, heat and moisture ingress (Deoju and Manandhar, 2004). This is the last operation through which coffee bean has to go before being actually made cup for brewing. In order to avoid the loss of aroma, coffee should be ground immediately before being made for brewing purpose as aroma is quickly lost from ground coffee (Hicks, 2002).

Brew preparation: Three up to five clean standard porcelain cups with $180 \mathrm{ml}$ capacity (Schonwald, Germany) per sample were prepared. Then 8 gram of coffee powder was put into each cup per sample. Fresh boiled $\left(90^{\circ} \mathrm{C}\right)$ water was poured into the cup with 8 gram of powder coffee up to about half of the cup. Then, the content of the cup was stirred in order to ensure the homogeneity of the mixture of coffee powder with boiled water in a cup. Before filing cup with fresh boiled water, the volatile aromatic quality and intensity parameter were evaluated by sniffing with three up to five certified panelists. Then the cup were filled with water to the size $(180 \mathrm{ml})$ and left to settle for about 3 minutes. Then, the floater was skimmed and the brew was ready for panelists within 8 minutes or beverage cooled to around 60 degree Celsius (drinkable temp.) for cup quality evaluation.

\section{SUMMARY AND CONCLUSION}

Even though Ethiopia is known to be the leading coffee producer and exporter in Africa and fifth major supplier 
of the global market, its share accounts for only $3 \%$ of the global coffee trade. Inappropriate harvesting methods, lack of appropriate drying and drying place are the major factors that could be limiting coffee quality and lowering market prices. To maintain quality of coffee, great effort is needed in creating awareness, encouraging use of raised beds, drying to proper moisture level and use of suitable storage facilities which inhibit the growth of molds. Storage facilities should be clean, cool, shaded, dry and well ventilated. Drying coffee on raised wire mesh beds and cemented ground with optimum thickness level $(2-3 \mathrm{~cm})$ but the practice of direct drying of coffee on ground leveled with mud and cow dung should be strongly discouraged.

In Ethiopia coffee growing area livelihood of small scale farmers are determined by the income from coffee sales and this income received from coffee depends on the quality of coffee, derived especially from post harvest primary processing. The use of immature cherries in the production of coffee is associated with poor quality coffee. The beans from such these cherries are prone to blackening during the drying process and coffee made from immature cherries has undesirable taste characteristics. Furthermore, the wet processing of coffee requires uniformly ripe cherries as immature fruit cannot be pulped. Therefore, the presence of significant quantities of immature cherries in a harvest presents problems in relation to coffee quality and problems of a technological nature. To avoid the quality problems posed by the use of green cherries, often some selective or semi-selective harvesting method is adopted.

Cost and availability of labor is often an important factor, alongside expected price, in harvest method selection. In the fact that Ethiopia possesses numerous genetic diversity and different type of coffee reputed for their unique cup-taste on the world market greatly favors the country to be more competitive.

Proper selection of cherry, adjustment of pulping machinery, Processing freshly Picked cherry, drying and storage Parchments are kept on as recommended Procedures rapid and more controllable fermentation is necessary in order to avoid congestion at the factory, to eliminate the possibility of occurrence of deleterious off-flavors and taints, such as 'sourness', 'stinkers' and 'onion flavor' .To ensure that coffee quality is improved during processing, each stage must be undertaken in the right manner and with facilities, which are in good order. Mixed stages of maturity and ripeness of cherries cause pulping and fermentation problems, Carefully sort the cherry by removing immature, green, under-ripe, overripe, dry, and diseased and insect damaged cherries as well as other plant leaves, twigs and any other foreign materials. Once the beans have been harvested and prepared, the organoleptic quality is affected by roasting.

According to the profile of temperature and length of roasting the taste and flavour perceived in the beverage is different. Generally Assessing and taking care of different coffee post harvest operations influence the quality of green coffee bean to supply and maintain the diversity of high quality specialty coffee to compete and sustain in the competitive market.

\section{REFFERENCES}

Agwanda CO, Baradat P, Eskes AB, Cilas C, Charrier A. 2003. Selection for Bean and Liquor Qualities within Related Hybrids of Arabica Coffee in Multi-Local Field Trials. Euphytica 131: 1-14.

Aklilu A, Ludi E. 2010. The Effect of Global Coffee Price Changes on Rural Livelihoods and Natural Resource Management in Ethiopia. A Case Study from Jimma Area. NCCR North-South Dialogue, no. 26. Swisspeace Bern, Switzerland.

Alemseged Assefa and Yeabsira Zewdu. 2014. Coffee export business in Ethiopia: Business start-up and operational manual. Ethiopian Coffee Export Association, Addis Ababa, Ethiopia

Antonym, M. and Surip, M. 2010. The influence of primary processing methods on cup taste of Arabica coffee from the Indonesian Island of Flores. Indonesian Coffee and Cocoa Research Institute, Indonesia. pp. 1-6

Anwar A., 2010. Assessment of Coffee Quality and its Related Problems in Jimma Zone of Oromia Regional State.

Aregba, A. W., P. Sebastian, and J. P. Nadeau. 2006. Stationary Deep Bed Drying: A Comparative Study Between A Logarithmic Model And A Non-Equilibrium Model. Journal of Food Engineering, 77(1): 27-40.

Bayetta B., Bahailu A., Gibramu T. 1998. Description and Production Recommendations for New Cultivar of Arabica coffee. EARO Research Report No. 34, Addis Ababa, Ethiopia. Pp: 1-13.

Bayetta B. 2001 Arabica Coffee Breeding For Yield and Resistance To Coffee Berry Disease (Colletotrichum Kahawae Sp. Nov.). Dissertation, University Of London, Imperial College Wye, U. K.

Behailu Weldsenbet and Solomon Endris .2006. The Influence of Shade during Fermentation Stage of Wet Processing On the Cup Quality of Arabica Coffee 21st International Scientific Conference On Coffee Science (ASIC). September 2006, Montpellier, France. Pp. 549-553. 11-15.

Behailu WS, Abrar S, Nigusie,M, Solomon E. 2008. A Review of coffee Processing and quality Research in Ethiopia. In: Girma A.,Bayeta B., and Tesfaye S.(ed). Coffee Diversity and Knowledge. Ethiopian. Institute of Agricultural Research .Pp: 307-316

Behailu, W., Abrar, S., Nugussie, M. And Solomon I., 2008. Coffee Processing and Quality Research in Ethiopia. In: Proceedings of a National Work Shop Four Decades of Coffee Research And Development In Ethiopia 
(Pp.307-316), 14-17 August 2007, EIAR, Addis Ababa, Ethiopia.

Berhanu Tsegaye, Ali Mohammed, Tesfaye Shimber, Yehenew Getachew and Essubalew Getachew. 2014. The influence of sun-drying methods and layer thickness on the quality of lowland Arabica coffee varieties at Gomma I, Southwestern Ethiopia. Research Journal of Agriculture and Environmental Management, 3(11): $547-554$

Beza Teklu, 2011. Effect of processing methods and drying materials on bean physical and sensory quality attributes of coffee (Coffea atbica L.) varieties at Gera and Jimma. M.Sc. Thesis presented to School of Graduate Studies of Jimma University, Collage of Agriculture and Veterinary Medicine, Jimma, Ethiopia. pp. 85.

Boot, W., 2006. Coffee Processing Handbook: From the cherry to the green bean-post harvesting coffee processing. Baarn, the Netherlands. pp. 173-192.

Brownbridge, J. M. And Eyassu, G.1968. The Quality of Some of Main Ethiopian Mild Coffee. Turrialba, 18(4): 361-372.

Brownbridge, J.M. and Sium, M.1971. Coffee processing research in Ehiopia. Fermentation and its effect on liquor quality, Kenya Coffee., Vol. 207, pp.214.

Cirovelásquez, H. J., L. C. Abudcano, and L. R. Pérezalegría. 2009. Numerical Simulation Of Thin Layer Coffee Drying By September, 2013 Effect Of Different Loading Densities On Selected Properties Of Dried Coffee Vol. 15, No.3237 Control Volumes. Coffee Sector Profile. Http://Www. Ugandainvest.Go.Ug/Index.Php/Agriculture/Coffee (Accessed June 6, 2013).

Corrêa1, P. C., O. Resende, D. M. Ribeiro. 2006. Drying Characteristics and Kinetics Of Coffee Berry. Revista Brasileira De Produtos Agroindustriais, Campina Grande, 8(1): 1-10.

Coste R., 1992. Characteristics And Composition Of Green Coffee. In Coffee: The Plant And The Product. The Macmillan Press Ltd. London and Basingstoke P.328.

CSA (Central Statistical Agency), 2013. Agricultural sample survey 2012/13 (2005 E.C.): A report on area and production of major crops. Statistical bulletin 532, Addis Ababa, Ethiopia .

DamanuTullu. 2008. Coffee production and marketing in Oromia Regional State. In: Proceedings of a National Work Shop Four Decades of Coffee Research and Development in Ethiopia. 14-17 August 2007, EIAR, Addis Ababa, Ethiopia. pp. 382-389.

Deoju, L. N. And Manandhar, S. 2004. An Overview Of Specialty Coffee. Tea and Coffee

Development Section, Kirtipur, Kathmandu, Nepal

DR Workefied Blog. 2013. The Difference between Semi-Washed and Fully-Washed Methods. Retrieved From: Http:/News.Drwakefield.Com/Coffee-Trading/The-Diffrence-Betweensemiwashed And-FullywashedMethods/80162181 On January 24, 2015.

EAFCA (East Africa Fine Coffee Association). 2010.East Africa Fine Coffee Association. Coffee Outlook. 2010

ECX (Ethiopian Commodity Exchanges). 2010. ECX Coffee contracts. Ethiopia Commodity

Elsa Tirfe. 2014. Quality performance of some early released coffee (Coffea arabica L.) varieties in Southwestern Ethiopia. M.Sc. Thesis presented to School of Graduate Studies of Jimma University, Collage of Agriculture and Veterinary Medicine, Jimma, Ethiopia. pp. 67.

Esayas A. 2005. Molecura genetic diversity study of forest coffee tree population in Ethiopia: Implication for conservation and Breeding. Doctoral thesis, Alnarp, Sweden.

Esayas K., 2009. Scaling up Higher Quality Coffee in East Africa- Experience from Ethiopia.

Exchange, Addis Ababa, Ethiopia.

FAO (Food and Agricultural Organization of the United Nation). 2010. Introduction To Coffee Drying. 'Good Hygiene Practices In The Primary Production Of Coffee. Retrieved From: Http://Www.Zecuppa.Com/Coffeetermsbean-Grading.Htm\#Top On November 5, 2014.

Girma M., 2003. Agrometriology Geographic Information System to Enhance Coffee V. 2002. Impact Of Specialty Coffee Increased Quality \& Profits For Small Holders. California, Colombia.

Hicks, A. 2002. Post-Harvest Processing and Quality Assurance for Specialty/Organic Coffee

Http://Www.Fao.Org/Docrep/003/X6939E/X6939e03.Htm (Accessed On: 08-07-2010).

Ibero (Uganda) Limited. 2005. Manual for Sustainable Coffee Production.

ICO (International Coffee Organization). 2014. Development Strategy for Coffee. ICC 105-16 Rev. 1, International Coffee Council 113th Session, 22 . 26 September 2014, London

ICO.2010. International Coffee Organization

http://tw.myblog.yahoo.com/jw!gGk. TCGBxzkQso4M2w/article?mid=393. Pp.1-20

2010.V(3):10.

International Coffee Organization (ICO). 2001. Available: http://www

ISO. 2000. International Standard ISO 9000: Quality management systems Fundamentals and vocabulary.

ITC.2002. International Tra de Center. Coffee, product and market development, an exporter"es guide. Unstad / Wto. Geneva. JUCAVM, Ethiopia. Pp: 91-110

Kristina Bagdonaite, 2011. Formation of Acryl amide during Roasting of Coffee http: \www.foodscience.tugraz. 
Leroy, T. Ribeyre, F. Bertrand, B. Charmetant, P. Dufour, M. Montagnon, C. Marraccini, P. and Pot, D. 2006. Genetics of coffee quality.Braz. J. Plant Physiol. 18 (1): 229-242.

Mayne R., Tola A., Kebede G .2002. Crisis in The Birth Place Of Coffee: The Coffee Crisis In the Kaffa Province Of Ethiopia. Oxfam International Research Papers.

Moreno, G., Moreno, E. and Cadena, G. 1995. Bean characteristics and cup quality of the Colombian variety (Coffea arabica) as judged by international tasting panels. In: the proceedings of the 16th International Scientific Colloquium on Coffee. Kyoto, Japan. pp. 574-583.

Muschler RG. 2001. Shade Improves Coffee Quality In A Sub-Optimal Coffee Zone Of Costa Rica. Agrofor. Syst. 51:131-139.

Musebe R, Agwenanda C, Mekon M. 2007. Primary Coffee Processing in Ethiopia: In Africa Crop Science Society; Africa Crop Science Conference Proceedings Vol.8.pp.1417-1421

Mutua, J. 2000. Post-Harvest Handling and Processing Of Green Coffee in African Countries.

Nebesny E, Grazyna B. 2006. Evaluation of sensory attributes of coffee brews from Robusta coffee roasted under different conditions, Eur. Food Res. Technol. 224: 159-165.

Pearl HM, Nagai C, Moore PH, Steiger DL, Osgood RV, Ming R.2004. Construction of A Genetic Map For Arabica Coffee. Theory. Appl. Genet.108: 829-835

Ponte S., 2002. Brewing a bitter cup? Deregulation, quality and the reorganization of the coffee marketing chain in E. Afr. J. Agrarian Chang. 2(2), 248-272.

Richard M., Charles A., Mitiku M. 2007. Primary coffee processing in Ethiopia: Patterns, constraints and determinates. Afr. Crop Sci. Conf. Proceed. 8:1417-1421.

Sivetz M. and N.W. Desrosier. 1979. Coffee Technology. The AVI Pub.Com.Westport, Connectricut U.S.A.

Sivetz, M. And Foote, H. E. 2004. Coffee Processing Technology. The Avi Publishing Company,Inc. Westport, Connecticut, U.S.

Solomon E, Behailu WS. 2006. The Quality of Wet Processed Arabica Coffee as Influenced by Depth of Parching and Covering Period during Drying. EIAR, Jimma Center. Pp: 544-548

Subedi RN .,2010. Comparative Analysis of Dry and wet processing of coffee with respect to Quality in Kaure District, Nepal. An M.Sc.Thesis submitted to Wagengen University. The Netherlands. Pp: 43-51

Taye Kufa, Ashenafi Ayano, Alemseged Yilma, Teshome Kumela,Wondiyfraw Tefera, 2011. The Contribution Of Coffee Research For Coffee Seed Development In Ethiopia, J. Agric. Res. Dev. 1(1): 009-016.

Thailand. Http://Www.Journal.Au.Edu/Au_Techno/2002/Jan2002/Article2.Pdf (Accessed On:

Van Der Vossen HAM., 1985. Coffee Selection and Breeding. In:Clifford MN, Willson KC (Eds.) Coffee Botany, Biochemistry And Production Of Beans And Beverage, Croom Helm, London Pp. 49-96

Wanyonyi, J. J. M. 1999. An Outline of Coffee Processing. Crop Production Division, Ministry Of Agriculture, Nairobi, Kenya

Wintegens JN. 2004. Coffee: Growing, Processing, Sustainable Production, a Guide Book for Growers, Processors, Traders, and Researchers.

Woelore WM. 1995. Parchment Arabica Coffee Storage. In: The Proceedings of the 16th International Scientific Colloquium on Coffee, Kyoto, Japan. Pp. 565-573.

Wootton, A.E. 1971. Report C.R. 14, Nairobi, May. Improvement, Proceedings of International

Wrigley, G. 1988. Coffee.Tropical Agricultural Series. Longman scientific and Technical, Longman group UK Limited, England.

Yigzaw D. 2005. Assessment of Cup Quality, Morphological, Biochemical and Molecular Diversity Of C. Arabica L. Genotypes Of Ethiopia. PhD Thesis, University Free State. P 97. 